\title{
Cholera toxin, E. coli heat-labile toxin, and non-toxic derivatives induce dendritic cell migration into the follicle-associated epithelium of Peyer's patches
}

\author{
NG Anosova ${ }^{1,2,3,4}$, S Chabot ${ }^{1,2,4}$, V Shreedhar ${ }^{1,2,3}$, JA Borawski ${ }^{1,2,3}$, BL Dickinson $^{1,2,3}$ and MR Neutra ${ }^{1,2}$
}

The follicle-associated epithelium (FAE) of Peyer's patches (PPs) transports antigens and microorganisms into mucosal lymphoid tissues where they are captured by subepithelial dendritic cells (DCs). Feeding of cholera toxin (CT) induced migration of subepithelial DCs to interfollicular T-cell areas within $24 \mathrm{~h}$. This study investigated short-term effects of CT, Escherichia coli heat-labile toxin, and non-toxic derivatives on DC migration. CT or CTB injected into ligated intestinal loops induced significant increase in CD11c + DCs within the FAE within $90 \mathrm{~min}$. In mice fed CT intragastrically, DC numbers in the FAE increased by $1 \mathrm{~h}$, were maximal by $2 \mathrm{~h}$, declined between 8 and $12 \mathrm{~h}$, and were reversed by $24 \mathrm{~h}$. Feeding of native LT, recombinant CTB, dibutyryl cyclic AMP, and to a lesser extent mutated CT(E29H) or mutated LT(R192G) had the same effect. Thus, both $A$ and $B$ subunits of enterotoxins, presumably acting through distinct signaling pathways, may promote capture of incoming antigens and pathogens by PP DCs.

\section{INTRODUCTION}

Mucosal immune responses to antigens, pathogens, and vaccines in the intestine are initiated at sites containing organized mucosal lymphoid tissues such as Peyer's patches (PPs). ${ }^{1}$ Mucosal lymphoid follicles are covered by a follicle-associated epithelium (FAE) that contains M cells specialized for transport of macromolecules, particles, and microorganisms across the epithelial barrier. ${ }^{2}$ Antigens and vaccines transported by $\mathrm{M}$ cells encounter a large cluster of CD11c + dendritic cells (DCs) located immediately under the FAE in the so-called "subepithelial dome" (SED) region that caps the mucosal lymphoid follicle. ${ }^{3-5}$ There is evidence that these DCs are attracted to the SED region of PP by chemokines, including CCL20 (MIP3 $\alpha$ ) and CCL9, which are produced by epithelial cells of the FAE. ${ }^{6-9}$ In addition, a few CD11c + DCs are present within the FAE of normal mice, both within $\mathrm{M}$-cell pockets and between other epithelial cells. ${ }^{6}$ We and others have observed that DCs of the SED region can take up incoming particles and bacteria. ${ }^{10-12}$ It seems reasonable to assume that movement of DCs into a frontline, intraepithelial position would promote rapid capture of antigens and microorganisms. This could serve to protect the host against mucosal infection and could affect the efficacy of mucosal vaccines.

We recently reported that FAE cells of normal mouse PP express apical Toll-like receptors (TLRs), including TLR2, -4, and -5 , and that intralumenal injection of TLR agonists had rapid, TLR-dependent effects on the FAE and associated DCs. ${ }^{13}$ TLR2 activators, including peptidoglycan and Pam3Cys, ${ }^{13}$ and the TLR5 activator flagellin (S. Chabot, M. Shawi, T. Eaves-Pyles, \& M.R. Neutra, unpublished) induced migration of DCs into the FAE within $1 \mathrm{~h}$. This very early effect, restricted to organized mucosal lymphoid tissues, would tend to promote antigen capture by local PP DCs and is consistent with the observed adjuvant effect of certain TLR activators when coadministered with antigen or formulated in mucosal vaccine delivery vehicles. $^{14,15}$ These observations raised the possibility that other bacterial products such as enterotoxins, which are strong mucosal adjuvants, might also have early FAE-specific effects.

${ }^{1}$ Gl Cell Biology Laboratory, Department of Medicine, Children's Hospital, Boston, Massachusetts, USA. ²Department of Pediatrics, Harvard Medical School, Boston, Massachusetts, USA. ${ }^{3}$ Present address: Acambis Inc., Cambridge, Massachusetts, USA (N.G.A.); Amgen Inc., Thousand Oaks, California, USA (V.S.); Novartis Inc., Cambridge, Massachusetts, USA (J.A.B.); The Research Institute for Children, New Orleans, Louisiana, USA (B.L.D.). ${ }^{4}$ These authors contributed equally to this work. Correspondence: MR Neutra (marian.neutra@childrens.harvard.edu) 
Cholera toxin (CT) and Escherichia coli heat-labile toxin (LT) are powerful mucosal adjuvants when coadministered with antigen, and their non-toxic, pentameric B subunits (CTB and LTB) also have immunomodulatory effects. ${ }^{16-18} \mathrm{CT}$ and CTB are rapidly endocytosed and transported across the FAE by $\mathrm{M}$ cells, ${ }^{19}$ and they are delivered into the SED region, which is rich in immature DCs. ${ }^{4}$ CT can bind via its B subunit to GM1 ganglioside on many cell types, including epithelial cells and DCs. Numerous studies have addressed the effects of CT on epithelial cells ${ }^{20,21}$ and the effects of CT and CTB on specific cells involved in development of adaptive immune responses. ${ }^{22-24}$ However, the innate responses of specific cells in organized lymphoid tissues in vivo are still not completely understood. Binding and endocytosis of CT holotoxin in intestinal epithelial cells results in a cascade of events that culminates in elevation of cyclic AMP (cAMP) and apical chloride secretion ${ }^{20}$ as well as activation of NF- $\kappa \mathrm{B}$ and expression of cytokines that have immunomodulatory effects. ${ }^{21,25}$ Recently, CT was shown to induce a rapid, transient increase in immature subepithelial DCs in the connective tissue of intestinal villi, followed later by the appearance of increased numbers of mature DCs in mesenteric lymph nodes. ${ }^{26}$ Although CT had no effect on DC numbers in PPs, ${ }^{26}$ migration within the PP was not examined. DCs in the organized lymphoid tissue of $\mathrm{PP}$ can mature and migrate to local T-cell areas without leaving the mucosa. ${ }^{4,6}$ Indeed, we previously reported that feeding of CT to mice induced movement of DCs from the SED region to the interfollicular T-cell areas of PP within $24 \mathrm{~h},{ }^{12}$ an effect consistent with toxin-induced DC maturation. ${ }^{4,22,23}$ Whether CT may have more rapid effects on the movements of DCs within PP was not examined.

The aim of this study was to explore the short-term effects of CT, LT, and their non-toxic derivatives on the movement of DCs in the mouse PP in vivo. The results show that intralumenal administration of native $\mathrm{CT}$, either by injection or peroral feeding, induced a rapid increase in the number of DCs within the FAE. DC migration into the FAE was detected within $1 \mathrm{~h}$ after intragastric feeding, was maximal at $6-8 \mathrm{~h}$, and reversed within $24 \mathrm{~h}$. Feeding of native LT, as well as CTB and mutated $\mathrm{CT}(\mathrm{E} 29 \mathrm{H})^{27}$ and LT(R192G) ${ }^{28}$ with reduced enzymatic activities, also induced DC migration into the FAE to varying degrees. Surprisingly, dibutyryl cyclic AMP (d-cAMP) had the same effect. Together, these results suggest that both A and B subunits, presumably acting through distinct signaling pathways, may trigger the release of chemokines that attract DCs into the FAE, perhaps to enhance the capture of microorganisms and particles prior to their entry into organized mucosal lymphoid tissues.

\section{RESULTS \\ CT and CTB subunits induce migration of DCs into the FAE in ligated intestinal loops}

To test the possibility that CT or CTB may have short-term effects on movements of PP DCs, ligated intestinal loops were injected with CT or CTB $(2.5 \mu \mathrm{g}$ in $100 \mu$ l phosphate-buffered saline (PBS)), and PPs were harvested 90 min later. Because recombinant CTB ( $\mathrm{rCTB}$ ) was not available for the ligated loop experiments, we used purified native CTB that contained no detectable ADP-ribosyltransferase activity (H. Shubeita, Calbiochem, personal communication). The distribution of DCs in PP was analyzed in sections stained with anti-CD11c (Figure 1). To visualize the boundary between the epithelium and connective tissue, basement membranes were stained with anti-laminin antibodies and nuclei were stained with 4,6-diamidino-2-phenylindole (DAPI) (Figure 1a). In normal untreated mice (data not shown) and PBS-injected controls (Figure 1b), many CD11c+ DCs were present in the SED region under the FAE and very few DCs were detected within the FAE, as reported previously. ${ }^{6,13}$ In PPs exposed to luminal CT (Figure 1c) or CTB (Figure 1d), the numbers of CD11c+ DCs in the FAE were clearly increased. Subepithelial DCs appeared to increase as well, although this could not be accurately quantitated in the crowded SED region (Figure 1d). Neither CT nor CTB had detectable effects on the numbers of DCs within the epithelium of villi, but subepithelial or lamina propria DCs were not counted (data not shown). Quantitation confirmed that the CT- and CTB-induced increases in DCs within the FAE were significant (Figure 2).

\section{CT, LT, and rCTB induce migration of DCs into the FAE when fed perorally}

To examine whether CT, CTB, and the related enterotoxin E. coli LT would induce DC migration into the FAE after peroral feeding, mice $(n=4)$ were intragastrically fed $50 \mu \mathrm{g}$ of CT, LT, or rCTB in $200 \mu \mathrm{l} \mathrm{PBS}$. Although oral doses of 5-10 $\mu \mathrm{g} \mathrm{CT}$ are sufficient to obtain an adjuvant effect in mice, $50 \mu \mathrm{g}$ was intentionally used here to produce local effects that could be detected morphologically in multiple distal PPs. This dose was used previously to demonstrate DC migration to T-cell areas of PP in tissue sections. ${ }^{12}$ Control mice $(n=3)$ were not fed. Distal ileal PPs were collected $6 \mathrm{~h}$ after feeding, and sections were stained with biotinylated anti-CD11c antibodies. In mice fed CT (Figure 3b), rCTB (Figure 3c), or LT (Figure 3d), the numbers of CD11c+ DCs per FAE section clearly increased over controls (Figure 3a). The numbers of CD11c + DCs located in the SED also appeared to increase after CT, rCTB, or LT feeding (Figure 3b-d). DCs were rarely observed in the villus epithelium of control animals, and no increase was detected after CT or LT exposure (data not shown).

\section{Kinetics of DC migration into the FAE of Peyer's patch after peroral administration of $\mathbf{C T}$}

To follow the time course of DC migration into the FAE in response to $\mathrm{CT}$, groups of four mice were intragastrically fed $50 \mu \mathrm{g}$ CT and their PPs were collected at 1, 2, 4, 6, 8, or $12 \mathrm{~h}$ post-feeding and prepared as described above. Clear increases in CD11c+ DCs within the FAE were noted at $1 \mathrm{~h}$ after feeding, and by $2 \mathrm{~h}$, DC numbers had dramatically increased relative to controls (Figure 4a). DC numbers in the FAE remained elevated up to $6-8 \mathrm{~h}$ but had declined at $12 \mathrm{~h}$. In a previous study, we observed that $24 \mathrm{~h}$ after CT feeding, the number of DCs within the FAE was indistinguishable from controls. ${ }^{12}$ Thus, CT resulted in rapid recruitment of DCs into the FAE, followed by gradual efflux. 

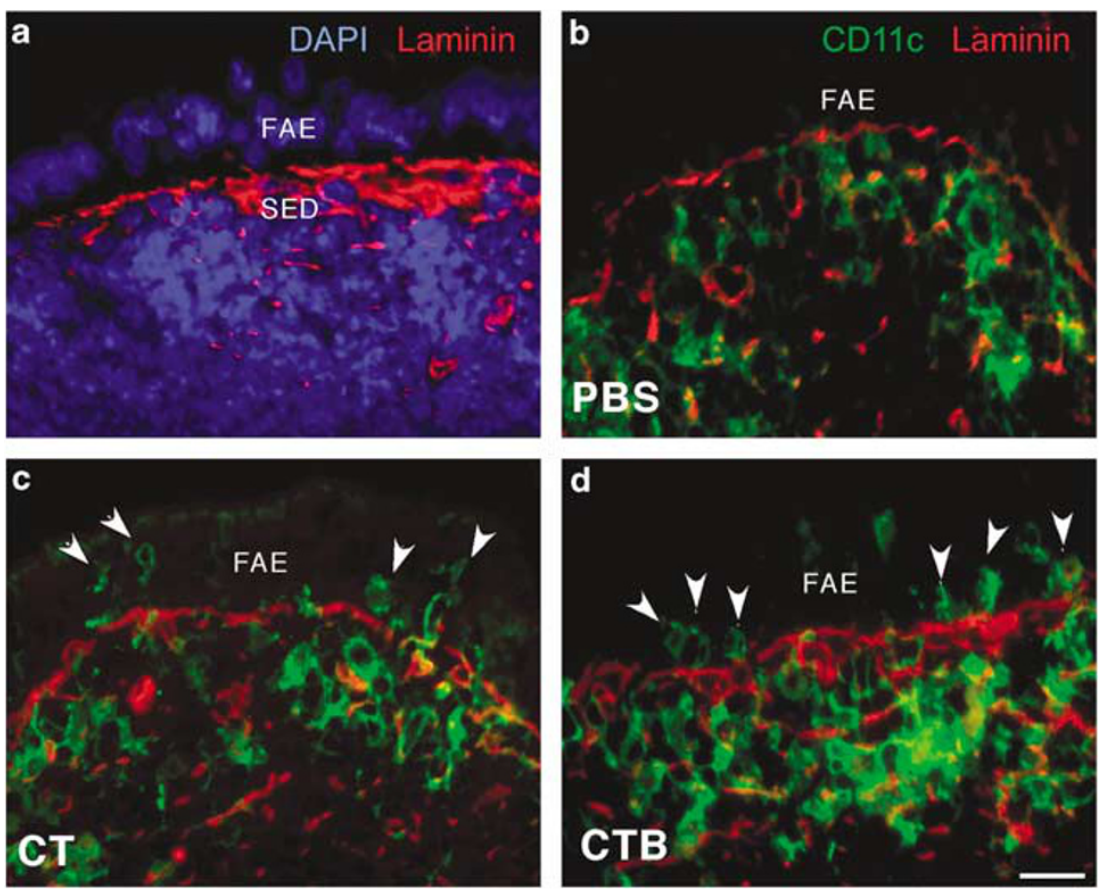

Figure 1 CT and CTB injected into ligated ileal loops induce migration of DCs into the FAE. (a) Control PP tissue section stained with DAPI (blue) and anti-laminin (red) to visualize the boundary between the SED region and the FAE. (b-d) Sections of PP domes stained for CD11c (green) and laminin (red), taken from ligated ileal loops injected with (b) PBS, (c) CT, or (d) CTB $90 \mathrm{~min}$ earlier. Increased numbers of DCs (arrowheads) are present in the FAE following injection of either CT or CTB. The images shown are representative of sections from four BALB/c mice per group. CT, cholera toxin; DAPI, 4,6-diamidino-2-phenylindole; DCs, dendritic cells; FAE, follicle-associated epithelium; PBS, phosphate-buffered saline; PPs, Peyer's patches; SED, subepithelial dome. $\mathrm{Bar}=10 \mu \mathrm{m}$.

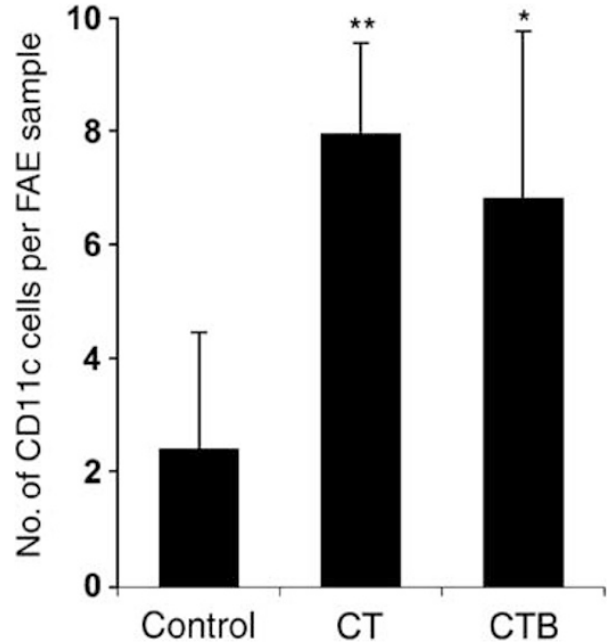

Figure 2 Quantitation of CD11C+ DCs in the FAE of BALB/c mice $(n=4)$ 90 min after intraluminal injection of CT, CTB, or PBS (control). Values are expressed as mean \pm s.d. of intraepithelial DCs per standard area as defined in Methods $\left({ }^{*} P<0.05 ;{ }^{* *} P<0.001\right.$, treated vs. control).

$\mathrm{CT}$, cholera toxin; DCs, dendritic cells; FAE, follicle-associated epithelium; PBS, phosphate-buffered saline.

\section{Movement of DCs into the FAE induced by mutated CT and LT toxins}

The fact that DC migration responses to CT and CTB were indistinguishable suggested that the enzymatic A subunit played no role in the effect observed. On this basis, we predicted that the mutated enterotoxins CT(E29H) and LT(R192G) would be as effective as native toxins in inducing DC migration because, although they have significantly reduced enzymatic activity, they have functional B subunits. ${ }^{27,28}$ We began by documenting the relative ADP-ribosyltransferase activities of the toxin preparations used in our experiments, as measured by toxin-mediated cAMP-dependent $\mathrm{Cl}^{-}$secretory responses (Isc) in polarized T84 cell monolayers on Transwell inserts over a $2 \mathrm{~h}$ time course. CTB is known to be devoid of activity in this assay ${ }^{29}$ and recombinant LTB (rLTB) lacked ADP-ribosyltransferase activity in the standard mouse Y-1 adrenal cell toxin assay (data not shown). In this experiment, rLTB served as a negative control and $1 \mathrm{nM}$ d-cAMP served as a positive control. As expected, d-cAMP, induced a rapid increase in Isc, and rLTB had no effect (Figure 4b). Strong $\mathrm{Cl}^{-}$secretory responses were induced by native CT and LT after a lag phase of about $30 \mathrm{~min}$ (CT) or $100 \mathrm{~min}$ (LT) as reported previously. ${ }^{20} \mathrm{CT}(\mathrm{E} 29 \mathrm{H})$ induced a $\mathrm{Cl}^{-}$secretory response that was similar in magnitude and timing to that elicited by native LT. In contrast, the Isc induced by LT(R192G) was lower than that induce by native LT or $\mathrm{CT}(\mathrm{E} 29 \mathrm{H})$ and exhibited an extended lag time (Figure $4 \mathbf{b}$ ).

The feeding protocol described above was then used to compare the DC migration effects of the mutated enterotoxins with those of CT and LT at $6 \mathrm{~h}$, the time of maximal effect as determined above. Groups of BALB/c mice $(n=5)$ were intragastrically fed $50 \mu \mathrm{g}$ of native CT, $50 \mu \mathrm{g}$ of native LT, or 50 or $100 \mu \mathrm{g}$ of recombinant CT(E29H) or LT(R192G) in $200 \mu \mathrm{l} \mathrm{PBS}$. An additional group of four mice was fed $50 \mu \mathrm{g}$ of rCTB. Control 

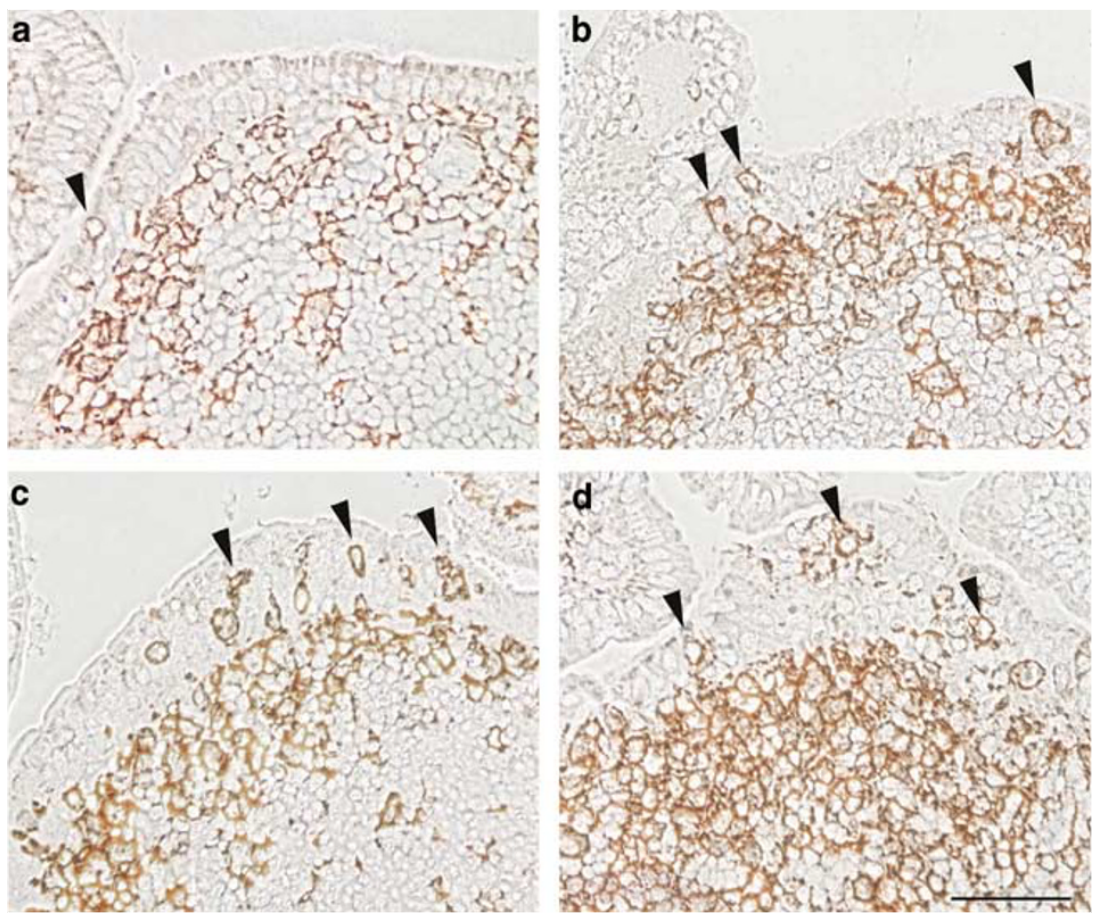

Figure 3 CT, LT, and rCTB fed perorally induce migration of CD11c + DCs into the FAE of PP. Groups of mice $(n=4)$ were fed (a) PBS, or $50 \mu \mathrm{g}$ of either (b) CT, (c) LT, or (d) rCTB, and distal PPs were collected $6 \mathrm{~h}$ later. Sections were treated with biotinylated anti-CD11c antibodies followed by avidin-HRP to visualize DCs within the FAE (arrowheads) and in the subepithelial dome region. CD11c+ DCs in the FAE and in the SED region were increased in mice fed with CT, LT, or rCTB. CT, cholera toxin; DCs, dendritic cells; FAE, follicle-associated epithelium; HRP, horseradish peroxidase; PBS, phosphate-buffered saline; PPs, Peyer's patches; rCTB, recombinant CTB; SED, subepithelial dome. Bar $=50 \mu \mathrm{m}$.

mice $(n=3)$ were not fed. Four PPs from each mouse were collected $6 \mathrm{~h}$ later, and DCs were counted in frozen sections stained with anti-CD11c antibodies. In PPs from control mice, very few CD11c+ DCs were present in the FAE and, as expected, DC numbers were significantly and comparably increased after feeding $50 \mu \mathrm{g}$ CT or LT (Figure 4c) or rCTB (data not shown). $\mathrm{CT}(\mathrm{E} 29 \mathrm{H})$ was somewhat less effective: $100 \mu \mathrm{g}$ was required to produce an effect comparable to that of $50 \mu \mathrm{g}$ of native CT or LT. Fifty micrograms of LT(R192G) showed no effect and $100 \mu \mathrm{g}$ had a measurable but insignificant effect (Figure 4c). Thus, although rCTB was sufficient to induce DC migration, the mutated toxins, with presumably normal B subunits, showed reduced effects that seemed to correlate roughly with the reduced enzymatic activities of their A subunits.

The fact that the recombinant reagents were produced in E. coli raised the possibility that the DC migration effects of mutated toxins or rCTB subunit may have been due in part to contamination with lipopolysaccharide (LPS) or peptidoglycan. We had previously observed that injection of $200 \mu \mathrm{l}$ of a solution containing $100 \mu \mathrm{g} \mathrm{ml}^{-1}$ E. coli LPS (a total dose of about 10,000 EU) into ligated loops of mice resulted in migration of DCs into the FAE within $90 \mathrm{~min} .{ }^{15} \mathrm{~A}$ similar effect was observed in mice fed $200 \mu \mathrm{l}$ PBS containing $1 \mathrm{mg}$ of Salmonella typhimurium LPS (equivalent to approximately $500,000 \mathrm{EU}$ ), and PP tissues were collected $6 \mathrm{~h}$ later (data not shown). Levels of LPS in the preparations of the recombinant reagents used in this study were analyzed by Limulus endotoxin assay. The rCTB preparation fed to mice contained very low LPS concentrations $\left(0.75 \mathrm{EU} \mathrm{ml}^{-1}\right)$, and thus only about $0.15 \mathrm{EU}$ was actually fed. Concentrations of LPS in the preparations of CT(E29H) and $\mathrm{LT}(\mathrm{R} 192 \mathrm{G})$ fed to mice were even lower $\left(0.12\right.$ and $0.16 \mathrm{EU} \mathrm{ml}^{-1}$, respectively). As these amounts are at least five orders of magnitude lower than the effective dose, it is unlikely that LPS contamination was responsible for the effects of $\mathrm{CCTB}, \mathrm{CT}(\mathrm{E} 29 \mathrm{H})$, or LT(R192G) on DC migration.

Because we had previously observed that TLR2 activators, including bacterial peptidoglycan and proteosomes composed of outer membrane proteins, induced DC migration into the FAE, ${ }^{13,30}$ it was important to test the possibility that traces of these bacterial components may have contaminated our toxin preparations and produced the effect observed. We therefore tested CT in an in vitro assay using transfected HEK 293 cells expressing TLR2. These cells respond to specific TLR2 agonists with release of the chemokine MIP3 $\alpha$ (CCL20), which can be detected by enzyme-linked immunosorbent assay as described previously. ${ }^{30}$ HEK cells expressing TLR2 (but not HEK cells containing a control plasmid) responded to peptidoglycan and proteosomes containing Neisserial outer membrane proteins as reported previously, ${ }^{30}$ but the TLR2-expressing cells showed no response to CT or CTB (data not shown).

\section{Elevation of CAMP induces DC migration into the FAE}

We then sought to evaluate the possible effect of the enzymatic A subunit on DC migration in vivo. The A subunit of CT or LT 

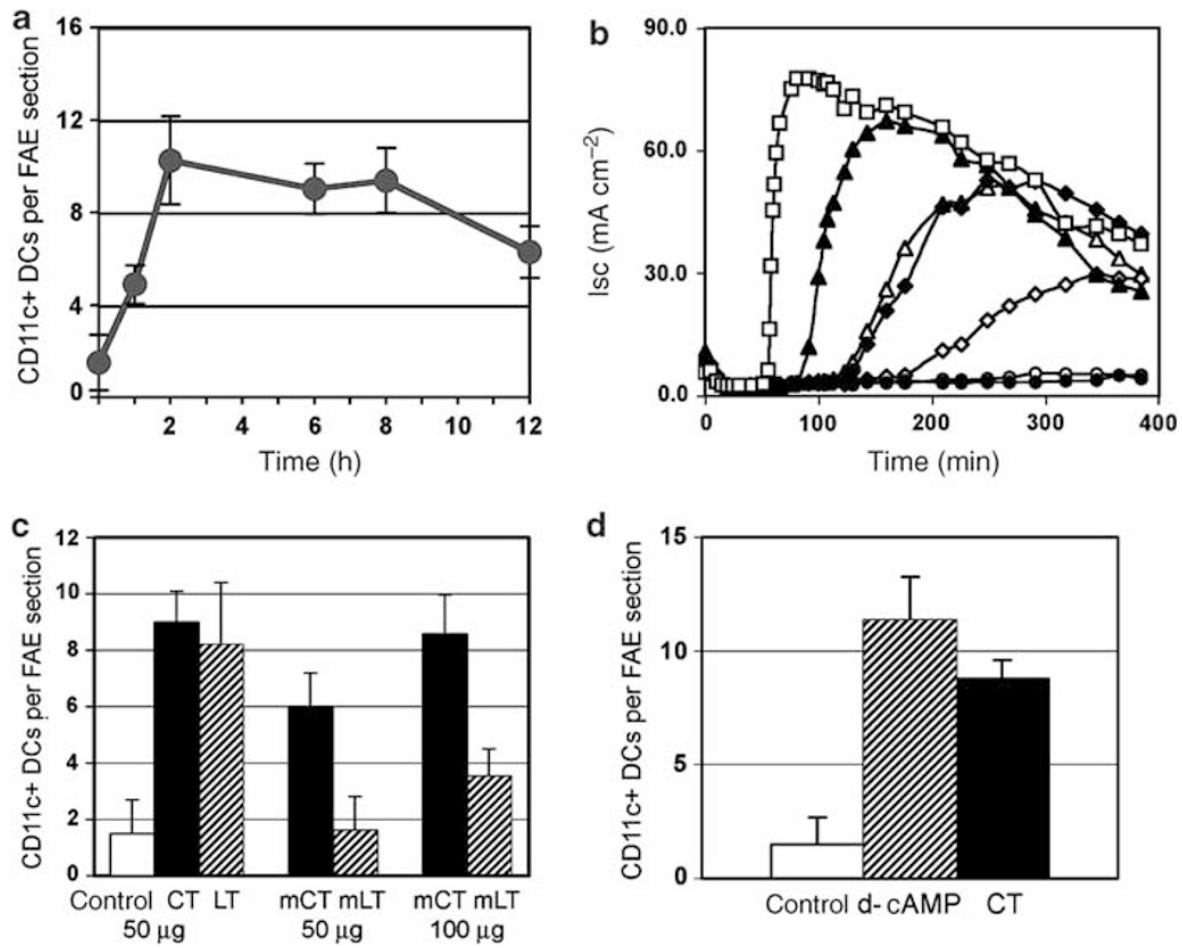

Figure 4 Analysis of DC migration effects induced by feeding of enterotoxins and derivatives. (a) Time course of DC migration into the FAE of PP after feeding native CT. Groups of mice $(n=4)$ were fed $50 \mu \mathrm{g}$ of CT and killed at 1, 2, 6, 8, or $12 \mathrm{~h}$ post-feeding, and sections from four distal PPs from each mouse were stained with anti-CD11c antibodies. Mean numbers ( \pm s.d.) of CD11c+ cells per FAE section for each group are shown. (b) Analysis of ADP-ribosyltransferase activity in the native and mutant enterotoxin preparations fed perorally, measured as elevation of short-circuit current (Isc) across confluent monolayers of T84 intestinal epithelial cells grown on Transwell filters. Results of a representative experiment of three are shown. The curves reflect elevation of intracellular cAMP produced by $10 \mathrm{~nm}$ of native CT (filled triangles), native LT (filled diamonds), mutant CT(E29H) (open triangles), mutant LT(R192G) (open diamonds), or rLTB (filled circles). A $1 \mathrm{~mm}$ solution of d-cAMP (open squares) served as a positive control and buffer alone (open circles) served as a negative control. (c) Numbers of DCs per FAE section in groups of mice $(n=4)$ fed either PBS (cont) or $50 \mu \mathrm{g}$ of native $\mathrm{CT}$, native $\mathrm{LT}$, mutant $\mathrm{CT}(\mathrm{E} 29 \mathrm{H})(\mathrm{mCT})$, mutant $\mathrm{LT}(\mathrm{R} 192 \mathrm{G})(\mathrm{mLT})$, or $100 \mu \mathrm{g}$ of mutant toxins. (Bars represent mean $\pm \mathrm{s}$.d.) After $50 \mu \mathrm{g}$ of $L T(R 192 G)$, numbers of DCs in the FAE were unchanged relative to controls. In mice fed $50 \mu \mathrm{g}$ of $\mathrm{CT}(\mathrm{E} 29 \mathrm{H})$, the average number of DCs per FAE section was increased but was significantly lower than that in mice treated with $50 \mu \mathrm{g}$ of native $\mathrm{CT}(P<0.0001)$. Hundred micrograms of $\mathrm{CT}(\mathrm{E} 29 \mathrm{H})$ had an effect comparable to that of $50 \mu \mathrm{g}$ native CT or LT $(P=0.3367)$. Hundred micrograms of $\mathrm{LT}(\mathrm{R} 192 \mathrm{G})$ had a significantly smaller effect than the same dose of $\mathrm{CT}(\mathrm{E} 29 \mathrm{H})(P<0.0001)$. (d) Injection of d-cAMP into ligated ileal loops mimics the effect of native CT on DC movement into the FAE. Mean numbers ( \pm s.d.) of CD11c + DCs per FAE of PP from groups of mice $(n=4)$ inoculated via ligated loops with $1 \mathrm{mM} \mathrm{d-cAMP} \mathrm{(cross-hatched} \mathrm{bar),}$ $50 \mu \mathrm{g} \mathrm{ml}^{-1} \mathrm{CT}$ (filled bar), or saline (open bar) are shown. CT, cholera toxin; DAPI, 4,6-diamidino-2-phenylindole; d-cAMP, dibutyryl cyclic AMP; DCs, dendritic cells; FAE, follicle-associated epithelium; PBS, phosphate-buffered saline; PPs, Peyer's patches.

cannot adhere to cells in the absence of B subunit and thus has no activity, but its effects on intestinal cells can be mimicked by intraluminal application of d-cAMP that readily penetrates cell membranes. We reasoned that if the ability of native enterotoxins to induce DCs migration into the FAE was mediated by B subunits alone, then d-cAMP should have no effect on DC migration in vivo. To test this, a solution containing $1 \mathrm{mM} \mathrm{d}$ cAMP was injected into ligated intestinal loops of four mice, each containing a PP. Ligated loops in other groups of four mice were injected with PBS containing $50 \mu \mathrm{g} \mathrm{ml}^{-1}$ of native $\mathrm{CT}$, or PBS alone. After $6 \mathrm{~h}, \mathrm{PPs}$ were harvested and processed, and CD11c+DCs were visualized and counted as above. After d-cAMP injection, DCs were dramatically increased in the FAE; the average number of DCs per FAE section was comparable or higher than that after injection of native CT (Figure 4d). Thus, elevation of intracellular cAMP in epithelial cells and/or DCs was associated with migration of DCs into the FAE.

\section{DCs from the SED region can move into the FAE and capture incoming pathogens}

DCs in the SED region and within the FAE of normal mice share phenotypic markers and are immature. ${ }^{6}$ On this basis, it is assumed that FAE DCs have come from the SED region and that the function of FAE DCs is to capture incoming pathogens. To test these assumptions, we sought to "label" SED DCs, follow their movement into the FAE, and then visualize the uptake of the M cell-tropic pathogen, reovirus. We had previously shown that fluorescent polystyrene microparticles transcytosed by $\mathrm{M}$ cells are cleared from the FAE by $24 \mathrm{~h}$ and accumulate within DCs in the SED region. These SED DCs can be identified at later time points by their microparticle content. ${ }^{12}$ Mice were thus fed red fluorescent polystyrene microparticles, and $24 \mathrm{~h}$ later the same mice were inoculated via ligated ileal loops with $10^{12}$ particles per $\mathrm{ml}$ of live reovirus (type 1 Lang). One hour later, PPs from these loops were 


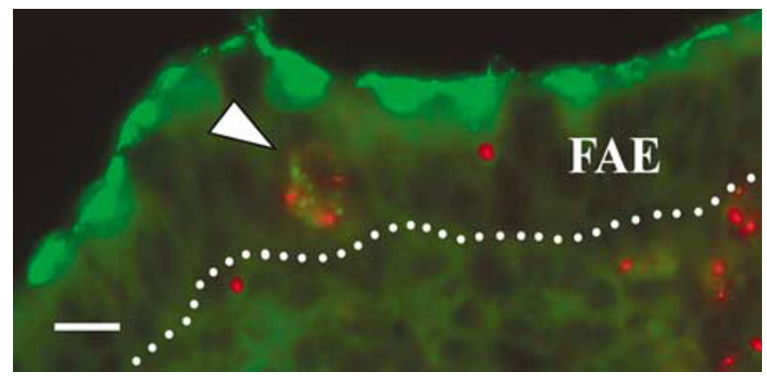

Figure 5 DCs loaded with fluorescent microparticles take up live reovirus in the FAE. Mice were fed red fluorescent microparticles, and $24 \mathrm{~h}$ later, ligated ileal loops were inoculated with live reovirus. PPs were collected and fixed $1 \mathrm{~h}$ later, and sections were stained with rabbit anti-reovirus serum followed by secondary FITC-conjugated antibodies. Reovirus (green) is concentrated at the apical poles of FAE cells. Some reovirus is colocalized with red fluorescent microparticles in a cell within the FAE (arrowhead). The dotted line indicates the basal surface of the FAE. DCs, dendritic cells; FAE, follicle-associated epithelium; FITC, fluorescein isothiocyanate; PPs, Peyer's patches. Bar $=10 \mu \mathrm{m}$.

collected, reovirus was labeled by immunostaining, and both virus and microparticles were visualized by fluorescence microscopy (Figure 5). Most of the labeled reovirus was located on the apical surface of the FAE, primarily on M cells, as expected. ${ }^{31}$ However, some labeled virus was colocalized with fluorescent microparticles in large cells, presumably DCs, within the FAE (Figure 5). The lack of luminal microparticles at the time point examined suggested that these microparticlecontaining cells had come from the SED region. These results are consistent with the hypothesis that DCs can migrate from the SED into the FAE to capture incoming pathogens.

\section{DISCUSSION}

Luminal administration of the bacterial enterotoxins CT and LT resulted in rapid movement of DCs into the FAE, a site of antigen and pathogen entry. At first glance, this appears to conflict with our previous observation that feeding of CT induced migration of DCs in the opposite direction, from the SED region to T-cell areas of PP. However, these events are separated in time. After a single oral dose of CT, DC movement into the FAE began within $1 \mathrm{~h}$, was maximal between 6 and $8 \mathrm{~h}$, had declined by $12 \mathrm{~h}$, and was reversed by $24 \mathrm{~h}$, at which time migration of DCs from the SED region to T-cell areas was observed. ${ }^{12}$ The rapidity of $\mathrm{DC}$ influx into the FAE and SED region of PP is similar to that of DC movement into the subepithelial connective tissue of villi (within $2 \mathrm{~h}$ after oral CT) reported by others. ${ }^{26}$ Although the subsequent efflux of DCs from the FAE (between 12 and 24h) was slower than that reported from villi, ${ }^{26}$ both observations are consistent with the hypothesis that enterotoxin binding to epithelial cells results in short-term release of epithelial chemokines that attract immature DCs and that later the toxins, endocytosed antigens, and other factors result in DC maturation and chemokine-directed migration to T-cell areas. Villus DCs must exit the mucosa to reach T-cell areas in mesenteric lymph nodes, whereas PP DCs need only move to adjacent T-cell areas within the PP. This migration pattern is in agreement with evidence obtained by others and is consistent with current views of PP DC function in vivo. ${ }^{4,6}$

DCs are known to reside in various epithelia under normal, unstimulated conditions. Intraepithelial DCs are present in the stratified epithelia of skin, ${ }^{32}$ tonsils, ${ }^{33}$ and vaginal mucosa. ${ }^{34}$ DCs are arranged in an orderly network within the airway epithelium $^{35}$ and are present in the villus epithelium of the small intestine ${ }^{36-38}$ of normal rodents. Movement of DCs into and out of intestinal epithelia in response to bacterial components other than toxins has been observed previously. Contact of Salmonella typhimurium with intestinal villus epithelium in vivo or intestinal cell monolayers in vitro triggered movement of DCs into the epithelium within $1 \mathrm{~h}$, followed by efflux. ${ }^{36} \mathrm{FAE}$ is composed of epithelial cells whose phenotype is distinct from that of intestinal villi or the colonic surface, however, and the DCs associated with the FAE of organized mucosal lymphoid tissues, such as PPs, are phenotypically distinct from DCs elsewhere in the mucosa or in the lymph nodes. ${ }^{3-7}$ The results obtained here and in our recent studies support the idea that FAE cells and DCs in organized mucosal lymphoid tissues are highly responsive to bacterial products, including enterotoxins and TLR agonists.

CT, CTB, and presumably LT are efficiently transcytosed by $\mathrm{M}$ cells ${ }^{19}$ and are known to have direct effects on DCs in vitro. For example, they induce DC maturation and upregulation of CCR7, ${ }^{2-24}$ a chemokine receptor that mediates DC migration toward MIP3 $\beta$ and secondary lymphoid organ chemokine gradients. ${ }^{39}$ In PPs, however, this would drive DCs toward organized T-cell areas and away from the FAE. ${ }^{4}$ Thus, it seems unlikely that the direct effects of these agents on DCs alone account for the rapid movement of DCs into the FAE that we observed. Rather, our observations are consistent with a growing body of evidence that production of chemokines by epithelial cells results in local gradients that attract DCs toward mucosal surfaces. ${ }^{4-9,40,41}$ Under normal conditions, these chemokine-receptor interactions appear to maintain the abundant DC population in the SED region, but epithelial CCL20 gene expression can be rapidly upregulated in response to bacterial components, ${ }^{40,42}$ including toxins. ${ }^{26}$ The CCL20 gene is a target for NF- $\kappa \mathrm{B}$, a transcription factor activated in epithelial cells in response to enteric pathogens. ${ }^{42,43} \mathrm{CT}, \mathrm{LT}$, and d-cAMP can all cause activation of NF- $\kappa \mathrm{B},{ }^{24,25}$ but it is not known whether this occurs in the FAE or whether upregulation of chemokine genes and enhanced chemokine synthesis in the FAE would be rapid enough to account for the DC migration that we observed at 1 and $2 \mathrm{~h}$. In contrast, others observed that CCL20 mRNA was increased in the villus epithelium within $1 \mathrm{~h}$ after oral feeding of CT, and significant DC migration into villi occurred by $2 \mathrm{~h} .{ }^{26}$ The possibility remains that the enterotoxins in this study induced a rapid release of intracellular chemokine stores as well as increased expression of chemokine genes in the FAE.

Increased release of CCL20, CCL9, and/or other chemokines by the FAE would explain the apparent increase in the number of DCs clustered in the SED region, but why did some DCs proceed further and enter the FAE? Plasma membrane molecules that participate in homotypic adherence and junction formation between epithelial cells, including E-cadherin and occludin, can 
be expressed by DCs and upregulated in response to inflammatory mediators and microbial pathogens. ${ }^{36,44}$ This would tend to promote and stabilize DC-epithelial interactions, but it would not explain why DCs migrate across the basal lamina to enter the epithelium in the first place. In the stratified epithelia of tonsils and skin during inflammation, there are complementary chemokine gradients within the epithelium itself, and CCL20 expression in the most apical cell layers accounts for DC migration of Langerhans cell precursors into the epithelium. ${ }^{45}$ In the single-layered epithelium of the intestine, more subtle gradients may occur, as secretory products are released by enterocytes into lateral intercellular spaces before diffusing into the connective tissue below. For example, the release of interleukin 8 from epithelial cells resulted in a cytokine gradient that attracted neutrophils into the lateral intercellular spaces. ${ }^{46}$ Similarly, when FAE cells are stimulated to release chemokines, local intercellular chemokine concentrations may be transiently elevated to levels sufficient to induce DCs to cross the basal lamina and enter the epithelium. The fact that the basal lamina of the FAE is highly fenestrated ${ }^{47}$ would facilitate this migration.

Available evidence indicates that the strongest adjuvant effects of CT and LT are closely linked to the ADP-ribosyltransferase activity of the A subunits. ${ }^{16}$ In contrast, amino-acid substitution mutants of the A subunits of CT and LT, combined with native $B$ subunits, have impaired ADP-ribosyltransferase activity but retain measurable adjuvant activity. ${ }^{27,28}$ The B subunits of CT and especially LT have immunomodulatory properties ${ }^{18,21}$ and CTB can enhance the uptake of coupled antigens through its epithelial cell-binding properties. ${ }^{17}$ However, CTB and LTB failed to induce the release of immunomodulatory cytokines from cultured T84 cells in vitro, ${ }^{21}$ and there is no evidence to date that CTB alone can evoke specific responses in intestinal epithelial cells. Little is known about the responses of the specialized FAE in vivo, however, and we do not know why purified or $\mathrm{CCTB}$, whether fed or injected into the intestinal lumen, induced DC migration into the FAE as effectively as did CT holotoxin in this study. The direction of this migration was most likely determined by factors from epithelial cells, and the possibility remains that CTB can activate as yet unidentified signaling pathways in the FAE. When applied to mononuclear cells in vitro, the pentameric B subunit of LTIIb indirectly induced NF- $\kappa$ B activation through interaction with TLR2, presumably by co-clustering in lipid rafts. ${ }^{48}$ Although CTB did not exhibit this TLR2-mediated effect, ${ }^{49}$ CTB crosslinks GM1 on apical membranes of intestinal epithelial cells and clusters receptors into lipid rafts, ${ }^{20}$ an event that is generally associated with activation of signal-transduction pathways. ${ }^{50}$

Given the multiple effects of enterotoxins or their derivatives on mucosal cells, it is not possible to measure separately the effect of rapid DC migration into the FAE on subsequent mucosal immune responses in vivo. It is clearly not a major mechanism of adjuvanticity because, although CTB alone induced early DC migration in this study, it has proven relatively ineffective as a mucosal adjuvant. ${ }^{16-18}$ The possibility remains that DC migration into the FAE is primarily a host defense mechanism designed to intercept pathogens, such as reovirus and Shigella that are taken up by $\mathrm{M}$ cells, and then infect epithelial cells via their more vulnerable basolateral surfaces. ${ }^{51,52}$ Much remains to be learned about the events that occur within and under the FAE during uptake of antigens and pathogens. Our observations support the idea that a broad range of microbial components can raise alerts in organized mucosal lymphoid tissues by activating rapid crosstalk between the FAE and underlying DCs.

\section{METHODS}

Animals and reagents. $\mathrm{BALB} / \mathrm{cAnNCr}$ female mice, $6-8$ weeks old and specific pathogen free, were from Charles River Laboratories (Wilmington, MA). Native CT, rCTB subunit, rCTB-peroxidase conjugate, non-recombinant purified CTB subunit (devoid of ADP-ribosyltransferase activity), and S. typhimurium LPS were from Calbiochem Biosciences (La Jolla, CA). Recombinant mutated CT(E29H) was provided by Wyeth-Lederle Vaccines (Pearl River, NY). Native E. coli LT, rLTB, and mutated LT(R192G) were a gift from John Clements (Tulane University, New Orleans, LA). HEK 293 cells transfected with a plasmid encoding murine TLR2 or a control vector were provided by Egil Lien (University of Massachusetts, Worcester, MA). Red fluorescent polystyrene microspheres containing phycoerythrin (diameter $0.2 \mu \mathrm{m}$ ) were from Polysciences (Warrington, PA). Reovirus T1L (Type 1/Human/ Ohio/Lang/1953) was grown in mouse L929 fibroblast cells in suspension culture. Purified virions were prepared, quantitated, and tested for purity as described previously. ${ }^{53}$

Administration of agents to mice. Water and food were withheld $4 \mathrm{~h}$ prior to administration of agents either by intragastric feeding or by injection into ligated loops of distal small intestine. For peroral (intragastric) feeding, agents were administrated in $200 \mu$ l saline using a $1 \mathrm{ml}$ syringe with a disposable 20-G, 1.5-inch blunt-end feeding needle (Popper, New Hyde Park, NY). After 1-24h, the mice were killed and the entire small intestine was removed and rinsed with cold PBS. At least four distal PPs were excised from each mouse, embedded in Tissue-Tek OCT embedding medium (Sakura Finetek, Torrance, CA), frozen in liquid nitrogencooled 2-methylbutane (Aldrich, Milwaukee, WI), and stored at $-20^{\circ} \mathrm{C}$. PPs from mice that were fed fluorescent microparticles and reovirus were fixed in PBS containing 3\% paraformaldehyde prior to freezing. For ligated loop experiments, animals were anesthesized by IP injection of Avertin solution, and a $3-5 \mathrm{~cm}$ segment of distal ileum containing a PP was ligated and injected with 100 or $200 \mu \mathrm{l}$ of PBS containing specific toxins or derivatives as described previously. ${ }^{31}$ Ligated segments were removed and the PPs were excised, frozen, and processed as described above.

Immunostaining and microscopic analysis. Frozen sections of PP from all mice were cut at $3-5 \mu \mathrm{m}$ on a Leica cryostat model CM3050 (Nussloch, Germany), mounted on S/P Superfrost Plus microscope slides (Allegiance, McGaw Park, IL), air-dried overnight, fixed with cold acetone for $2 \mathrm{~min}$, and stained as described below. Coverslips were mounted with an aqueous solution containing Mowiol 4-88 (Calbiochem) and glycerol (Sigma, St Louis, MO) in $0.2 \mathrm{~m}$ Tris buffer, $\mathrm{pH}$ 8.5. Stained tissue sections were examined and photographed using a Zeiss Axiophot microscope (Zeiss, Germany) equipped with a digital camera.

To visualize DCs in PP sections from intragastrically fed mice, slides were treated with $1 \% \mathrm{H}_{2} \mathrm{O}_{2}$ to neutralize endogenous peroxidase, blocked with PBS containing $2 \%$ goat serum, and treated with biotinylated anti-CD11c antibodies (BD Pharmingen, San Diego, CA) followed by avidin-conjugated horseradish peroxidase (Sigma) and Sigma Fast 3,3'diaminobenzidine substrate solution. To visualize DCs in tissues from ligated loop experiments, acetone-fixed sections were blocked with PBS containing $2 \%$ goat serum followed by the avidin-biotin blocking kit (Vector Laboratories, Burlingame, CA). Sections were then treated with biotin-conjugated rat anti-mouse-CD11c (BD Pharmingen) followed by Streptavidin-Alexa 555 and, in some cases, rabbit-anti-mouse 
laminin (ICN) followed by goat anti-rabbit-Alexa 488 (Molecular Probes, Carlsbad, CA). 4,6-Diamidino-2-phenylindole was used for staining of nuclei. Normal rabbit IgG (Santa Cruz Laboratories, Santa Cruz, CA), purified rat IgG2 a (eBioscience, San Diego, CA), or omission of primary antibodies served as negative controls. To visualize red fluorescent microspheres and reovirus in paraformaldehyde-fixed tissues, sections were stained with polyclonal rabbit anti-reovirus antiserum $(1: 2,000)$ followed by secondary biotinylated anti-rabbit antibodies and streptavidin-fluorescein isothiocyanate.

Quantitation and statistics. To determine the relative numbers of DCs in FAE samples after intragastric feeding of agents, four distal PPs from each of four mice were sectioned through, and a minimum of six sections obtained from the central region of each PP were stained as described above. For each PP, one section that included the apex of one or more follicle domes was selected and the number of CD11c + cells within the entire length of each FAE was recorded. Ligated loop experiments involved only one PP of each mouse; the treated PP was sectioned through and six separate FAEs from each PP that included the apex of a follicle dome were selected and photographed. A segment of FAE measuring $223 \mu \mathrm{m}$ in length was demarcated and all CD11c + cells located within the FAE segment were counted. To quantitate DCs within the villus epithelium of the same mice, a single villus sectioned longitudinally and lying within a $0.04 \mathrm{~mm}^{2}$ area of the selected section was identified, and the number of $\mathrm{CD} 11 \mathrm{c}+$ cells within the epithelium was recorded. Data were expressed as mean DCs per FAE segment or per villus epithelium \pm s.e.m. Thus, in all experiments, the results for each treatment group of four mice were based on a total of 24 separate samples of FAE or villus. Statistical analyses were performed using Instat (GraphPad Software). Differences between groups were analyzed using the Bonferroni multiple comparison one-way analysis of variance or an unpaired $t$-test, and differences with $P<0.05$ were considered statistically significant.

Electrophysiology. The human intestinal epithelial cell line T84 was cultured as described previously. ${ }^{20,54} \mathrm{~T} 84$ cells were seeded at confluent density onto $0.33 \mathrm{~cm}^{2}$ polycarbonate Transwell inserts (Costar, Corning, NY) coated with a dilute collagen solution. Transepithelial resistances attained stable levels (ca. $\geqslant 1,000 \Omega \mathrm{cm}^{-2}$ ) 7 days post-plating. Monolayers were equilibrated in Hank's balanced salt solution at $37^{\circ} \mathrm{C}$, and short circuit current (Isc) and transepithelial resistance were measured with a dual voltage-current clamp device (University of Iowa, Iowa City, IA) as described previously. ${ }^{54}$ Cells were pulsed with a $25-\mu \mathrm{A}$ current and the change in Isc was recorded until a stable Isc was obtained. Toxins or derivatives $(10 \mathrm{~nm})$ were then added to the apical compartment and cells were maintained at $37^{\circ} \mathrm{C}$ over a 2-h time course during which changes in Isc were recorded at timed intervals.

Endotoxin assay. LPS contamination in the native toxin, mutant toxin, and recombinant B subunit preparations was determined by Limulus assay (Bio-Whittaker, Walkersville, $\mathrm{MD}$ ) according to the manufacturer's instructions. The concentration of endotoxin in test samples was calculated from their spectrophotometric absorbance at $405 \mathrm{~nm}$ using an LPS solution provided by the manufacturer as standard.

HEK 293 cell assay for MIP3 $\alpha$ release. HEK 293 cells transfected with plasmids encoding murine TLR2 or with control vector were seeded in 96-well plates at a density of $2.5 \times 10^{4}$ cells per well. When confluency was reached, cells were incubated for $24 \mathrm{~h}$ in triplicate with $10 \mu \mathrm{g} \mathrm{ml}^{-1}$ peptidoglycan, $10 \mu \mathrm{g} \mathrm{ml}^{-1}$ proteosomes containing Neisserial outer membrane proteins, $10 \mu \mathrm{g} \mathrm{ml}^{-1} \mathrm{CT}$ or purified CTB, or no additives. Levels of MIP3 $\alpha$ in the culture medium were analyzed with a quantitative sandwich enzyme immunoassay (ELISA) technique using an MIP3 $\alpha$ protein standard provided by the manufacturer (R\&D Systems, Minneapolis, MN). Statistical analyses were performed with Instat (GraphPad Software), and differences between groups were analyzed with the Bonferroni multiple comparison one-way analysis of variance.

\section{ACKNOWLEDGMENTS}

The assistance of Stephanie Farrant and Jessica Wagner is gratefully acknowledged. We thank Dr Clements for providing native and mutated LT, Dr Kushroo Shroff and Wyeth-Lederle Vaccines for providing mutated CT, Dr Lien for providing HEK 293 cell-transfected murine TLR2, and Dr Wayne Lencer for providing valuable advice and electrophysiology equipment. This work was supported by NIH Research Grant HD17557 (to M.R.N.) and NIH Center Grant DK34854 to the Harvard Digestive Diseases Center.

\section{DISCLOSURE}

The authors declared no conflict of interest.

(C) 2008 Society for Mucosal Immunology

\section{REFERENCES}

1. Strober, W. \& McGhee, J.R. Inductive and effector tissues and cells of the mucosal immune system. In Mucosal Immunology (Mestecky J., Lamm M., McGhee J., Bienenstock J., Mayer L. \& Strober W., eds) 371-374 (Academic Press, New York, 2005).

2. Neutra, M.R., Mantis, N.J. \& Kraehenbuhl, J.-P. Collaboration of epithelial cells with organized mucosal lymphoid tissues. Nat. Immunol. 2, 1004-1009 (2001).

3. Kelsall, B.L. \& Strober, W. Distinct populations of dendritic cells are present in the subepithelial dome and T cell regions of murine Peyer's patches. J. Exp. Med. 183, 237-247 (1996).

4. Iwasaki, A. \& Kelsall, B.L. Localization of distinct Peyer's patch dendritic cell subsets and their recruitment by chemokines macrophage inflammatory protein (MIP)-3alpha, MIP-3beta, and secondary lymphoid organ chemokine. J. Exp. Med. 191, 1381-1394 (2000).

5. Cook, D.N., Prosser, D.M., Forster, R., Zhang, J., Kuklin, N.A., Abbondanzo, S.J. et al. CCR6 mediates dendritic cell localization, lymphocyte homeostasis, and immune responses in mucosal tissue. Immunity 12, 495-503 (2000)

6. Iwasaki, A. \& Kelsall, B. Unique functions of CD11b+, CD8a+, and double negative Peyer's patch dendritic cells. J. Immunol. 166, 4884-4890 (2001).

7. Ruedl, C., Reiser, C., Bock, G., Wick, G. \& Wolf, G. Phenotypic and functional characterization of CD11C+ dendritic cell population in mouse Peyer's patches. Eur. J. Immunol. 26, 1801-1806 (1996).

8. Tanaka, Y., Imai, T., Baba, M., Ishikawa, I., Uehira, M., Nomiyama, H. et al. Selective expression of liver and activation-regulated chemokine ( $\triangle A R C)$ in intestinal epithelium in mice and humans. Eur. J. Immuno/ 29, 633-642 (1999)

9. Zhao, X., Sato, A., DelaCruz, C.S., Linehan, M., Luegering, A., Kucharzik, T. et al. CCL9 is secreted by the follicle-associated epithelium and recruits dome region Peyer's patch CD11b+ dendritic cells. J. Immunol. 171, 2797-2803 (2003).

10. Hopkins, S.A., Niedergang, F., Corthesy-Theulaz, I.E. \& Kraehenbuhl, J.P. A recombinant Salmonella typhimurium vaccine strain is taken up and survives within murine Peyer's patch dendritic cells. Cell. Microbiol. 2, 59-68 (2000).

11. Pron, B., Boumalia, C., Jaubert, F., Berche, P., Milon, G., Geissman, F. et al. Dendritic cells are early cellular targets of Listeria monocytogenes after intestinal delivery and are involved in bacterial spread in the host. Cell. Microbiol. 3, 331-340 (2001).

12. Shreedhar, V.K., Kellsall, B.L. \& Neutra, M.R. Cholera toxin induces migration of dendritic cells from the sub-epithelial dome region to $T$ and $B$ cell areas of Peyer's patches. Infect. Immun. 71, 504-509 (2003).

13. Chabot, S., Wagner, J.S., Farrant, S. \& Neutra, M.R. Toll-like receptors regulate the gatekeeping functions of the intestinal follicle-associated epithelium. J. Immunol. 176, 4275-4283 (2006).

14. Lee, S.E., Kim, S.Y., Jeong, B.C., Kim, Y.R., Bae, S.J., Ahn, O.S. et al. A bacterial flagellin, Vibrio vulnificus FlaB, has a strong mucosal adjuvant activity to induce protective immunity. Infect. Immun. 74, 694-702 (2006).

15. Chabot, S., Brewer, A., Lowell, G., Plante, M., Cyr, S., Burt, D.S. et al. A novel intranasal Protollin-based measles vaccine induces mucosal and systemic neutralizing antibody responses and cell-mediated immunity in mice. Vaccine 23, 1374-1383 (2005).

16. Elson, C.O. \& Dertzbaugh, M.T. Mucosal adjuvants. In Mucosal Immunology (Mestecky, J., Lamm, M., McGhee, J., Bienenstock, J., Mayer, L. \& Strober, W., eds) 967-986 (Academic Press, New York, 2005). 
17. Holmgren, J., Adamsson, J., Anjuère, F., Clemens, J., Czerkinsky, C., Eriksson, K. et al. Mucosal adjuvants and anti-infection and anti-immunopathology vaccines based on cholera toxin, cholera toxin $B$ subunit and CpG DNA. Immunol. Lett. 97, 181-188 (2004).

18. Simmons, C.P., Ghaem-Magami, M., Petrovska, L., Lopes, L., Chain, B.M., Williams, N.A. et al. Immunomodulation using bacterial enterotoxins. Scand. J. Immunol. 53, 218-226 (2001).

19. Frey, A., Giannasca, K.T., Weltzin, R.A., Giannasca, P.J., Reggio, H., Lencer, W.I. et al. Role of the glycocalyx in regulating access of microparticles to apical plasma membranes of intestinal epithelial cells: implications for microbial attachment and oral vaccine targeting. J. Exp. Med. 184, 1045-1060 (1996).

20. Lencer, W.I. Microbes and microbial toxins: paradigms for microbial-mucosal interactions. $V$. cholera: invasion of the intestinal epithelial barrier by a stably folded protein toxin. Am. J. Physiol. Gastrointest. Liver Physiol. 280, G781-G786 (2001).

21. Soriani, M., Bailey, L. \& Hirst, T.R. Contribution of the ADP-ribosylating and receptor-binding properties of cholera-like enterotoxins in modulating cytokine secretion by human intestinal epithelial cells. Microbiology 148 , 667-676 (2002).

22. Bagley, K.C., Abdelwahab, S.F., Tuskan, R.G., Fouts, T.R. \& Lewis, G.K. Cholera toxin and heat-labile enterotoxin activate human monocytederived dendritic cells and dominantly inhibit cytokine production through a cyclic AMP-dependent pathway. Infect. Immun. 70, 5533-5539 (2002).

23. Gagliardi, M.C., Sallusto, F., Marinaro, M., Langenkamp, A., Lanzavecchia, A. \& De Magistris, M.T. Cholera toxin induces maturation of human dendritic cells and licenses them for Th2 priming. Eur. J. Immunol. 30, 2394-2403 (2000).

24. Kawamura, Y.I., Kawashima, R., Shirai, Y., Kato, R., Hamabata, T., Yamamoto, M. et al. Cholera toxin activates dendritic cells through dependence on GM1-ganglioside which is mediated by NF-kappaB translocation. Eur. J. Immunol. 33, 3205-3212 (2003).

25. Blumberg, R.S., Pitman, R.S., Taylor, C.T. \& Colgan, S.P. Cholera toxin potentiates influences of IFN-gamma through activation of NF-kappaB and release of tumor necrosis factor-alpha. J. Interferon. Cytokine Res. 25, 209-219 (2005).

26. Anjuere, F., Luci, C., Lebens, M., Rousseau, D., Hervouet, C., Milon, G. et al. In vivo adjuvant-induced mobilization and maturation of gut dendritic cells after oral administration of cholera toxin. J. Immunol. 173, 5103-5111 (2004)

27. Tebbey, P.W., Scheuer, C.A., Peek, J.A., Zhu, D., LaPierre, N.A., Green, B.A. et al. Effective mucosal immunization against respiratory syncytial virus using purified $\mathrm{F}$ protein and a genetically detoxified cholera holotoxin CT-E29H. Vaccine 18, 2723-2734 (2000).

28. Dickinson, B.L. \& Clements, J.D. Dissociation of E. coli heat-labile enterotoxin adjuvanticity from ADP-ribosyltransferase activity. Infect. Immun. 63, 1617-1623 (1995).

29. Rodighiero, C., Fujinaga, Y., Hirst, T. \& Lencer, W.I. A cholera toxin B-subunit variant that binds ganglioside $\mathrm{Gm} 1$ but fails to induce toxicity. J. Biol. Chem. 276, 36939-36945 (2001).

30. Chabot, S., Chernin, T.S., Shawi, M., Wagner, J.S., Farrant, S., Burt, D.S. et al. TLR2 activation by proteosomes promotes uptake of particulate vaccines at mucosal surfaces. Vaccine $25,5348-5358$ (2007).

31. Helander, A., Silvey, K.J., Mantis, N.J., Hutchings, A.B., Chandran, K., Lucas, W.T. et al. The viral sigma1 protein and glycoconjugates containing alpha 2-3-linked sialic acid are involved in type 1 reovirus adherence to $M$ cell apical surfaces. J. Virol. 77, 7964-7977 (2003).

32. Robert, C., Fuhlbrigge, R.C., Kieffer, J.D., Ayehunie, S., Hynes, R.O. Cheng, G. et al. Interaction of dendritic cells with skin endothelium: a new perspective on immunosurveillance. J. Exp. Med. 189, 627-636 (1999).

33. Okato, S., Magari, S., Yamamoto, Y., Sakanaka, M. \& Takahashi, H. An immuno-electron microscopic study on interactions among dendritic cells, macrophages and lymphocytes in the human palatine tonsil. Arch. Histol. Cytol. 52, 231-240 (1989).

34. Miller, C.J., McChesney, M. \& Moore, P.F. Langerhans cells, macrophages and lymphocyte subsets in the cervix and vagina of rhesus macaques. Lab. Invest. 67, 628-634 (1992).
35. Holt, P.G., Schon-Hegrad, M.A. \& McMenamin, P.G. Dendritic cells in the respiratory tract. Int. Rev. Immunol. 6, 139-149 (1990).

36. Rescigno, M., Urbano, M., Valzasina, B., Francolini, M., Rotta, G., Bonasio, R. et al. Dendritic cells express tight junction proteins and penetrate gut epithelial monolayers to sample bacteria. Nat. Immunol. 2, 361-367 (2001)

37. Niess, J.H., Brand, S., Gu, X., Landsman, L., Jung, S., McCormick, B.A. et al. CX3CR1-mediated dendritic cell access to the intestinal lumen and bacterial clearance. Science 307, 254-258 (2005).

38. Chieppa, M., Rescigno, M., Huang, A.Y. \& Germain, R.N. Dynamic imaging of dendritic cell extension into the small bowel lumen in response to epithelial cell TLR engagement. J. Exp. Med. 203, 2841-2852 (2006).

39. Forster, R., Mattis, A.E., Kremmer, E., Wolf, E., Brem, G., Lipp, M. et al. A putative chemokine receptor, blr 1 , directs $B$ cell migration to defined lymphoid organs and specific anatomic compartments of the spleen. Cell 87, 1037-1047 (1996).

40. Sierro, F., Dubois, B., Coste, A., Kaiserlian, D., Kraehenbuhl, J.P. \& Sirard, J.C. Flagellin stimulation of intestinal epithelial cells triggers CCL20-mediated migration of dendritic cells. Proc. Natl. Acad. Sci. USA 98, 13722-13727 (2001).

41. Le Borgne, M., Etchart, N., Goubler, A., Lira, S.A., Sirard, J.C., van Rooijen, N. et al. Dendritic cells rapidly recruited into the epithelial tissues via CCR6/CCL20 are responsible for CD8+ T cell crosspriming in vivo. Immunity 24, 191-201 (2006).

42. Izadpanah, A., Dwinell, M.B., Eckmann, L., Varki, N.M. \& Kagnoff, M.F. Regulated MIP-3alpha/CCL20 production by human intestinal epithelium: mechanism for modulating mucosal immunity. Am. J. Physiol. Gastrointest. Liver Physiol. 280, G710-G719 (2001).

43. Elewaut, D., DiDonato, J.A., Kim, J.M., Truong, F., Eckmann, L. \& Kagnoff, M.F. NF-kappa B is a central regulator of the intestinal epithelial cell innate immune response induced by infection with enteroinvasive bacteria. J. Immunol. 163, 1457-1466 (1999).

44. Jakob, T. \& Udey, M.C. Regulation of E-cadherin-mediated adhesion in Langerhans cell-like dendritic cells by inflammatory mediators that mobilize Langerhans cells in vivo. J. Immunol. 160, 4067-4073 (1998).

45. Vanbervliet, B., Homey, B., Durand, I., Massacrier, C., Ait-Yahia, S., de Bouteiller, O. et al. Sequential involvement of CCR2 and CCR6 ligands for immature dendritic cell recruitment: possible role at inflamed epithelial surfaces. Eur. J. Immunol. 32, 231-242 (2002).

46. Gewirtz, A.T., Siber, A.M., Madara, J.L. \& McCormick, B.A. Orchestration of neutrophil movement by intestinal epithelial cells in response to Salmonella typhimurium can be uncoupled from bacterial internalization. Infect. Immun. 67, 608-617 (1999).

47. McClugage, S.G., Low, F.N. \& Zimmy, M.L. Porosity of the basement membrane overlying Peyer's patches in rats and monkeys. Gastroenterology 91, 1128-1133 (1986).

48. Liang, S., Wang, M., Triantafilou, K., Triantafilou, M., Nawar, H.F., Russell, M.W. et al. The A subunit of type llb enterotoxin (LT-llb) suppresses the proinflammatory potential of the $B$ subunit and its ability to recruit and interact with TLR2. J. Immunol. 178, 4811-4819 (2007).

49. Hajishengallis, G., Tapping, R.I., Martin, M.H., Nawar, H., Lyle, E.A., Russell, M.W. et al. Toll-like receptor 2 mediates cellular activation by the B subunits of type II heat-labile enterotoxins. Infect. Immun. 73, 1343-1349 (2005).

50. Simons, K. \& Toomre, D. Lipid rafts and signal transduction. Nat. Rev. Mol. Cell Biol. 1, 31-39 (2000).

51. Fleeton, M.N., Contractor, N., Leon, F., Wetzel, J.D., Dermody, T.S. \& Kelsall, B.L. Peyer's patch dendritic cells process viral antigen from apoptotic epithelial cells in the intestine of reovirus-infected mice. J. Exp. Med. 200, 235-245 (2004).

52. Sansonetti, P.J. \& Phalipon, A. M cells as ports of entry for enteroinvasive pathogens: mechanisms of interaction, consequences for the disease process. Semin. Immunol. 11, 193-203 (1999).

53. Bodkin, D.K., Nibert, M.L. \& Fields, B.N. Proteolytic digestion of reovirus in the intestinal lumens of neonatal mice. J. Virol. 63, 4676-4681 (1989).

54. Dharmsathaphorn, K. \& Madara, J.L. Established intestinal cell lines as model systems for electrolyte transport studies. Methods Enzymol. 192, 354-359 (1990). 